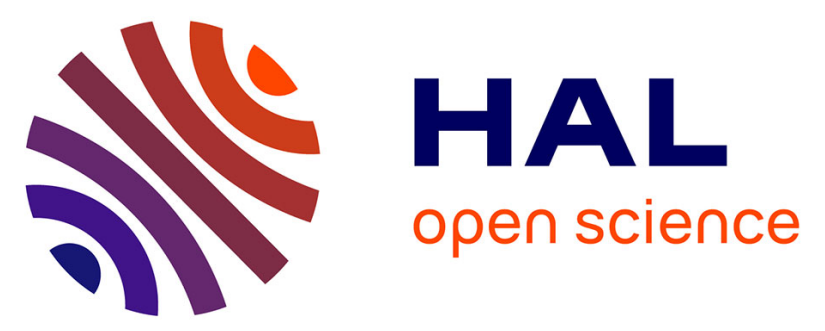

\title{
Formal and informal external linkages and firms' innovative strategies. A cross-country comparison
}

Isabel Maria Bodas Freitas, Tommy Clausen, Roberto Fontana, Bart

Verspagen

\section{- To cite this version:}

Isabel Maria Bodas Freitas, Tommy Clausen, Roberto Fontana, Bart Verspagen. Formal and informal external linkages and firms' innovative strategies. A cross-country comparison. Journal of Evolutionary Economics, 2008, 21 (1), pp. 91-119. 10.1007/s00191-010-0188-y . hal-01487470

\section{HAL Id: hal-01487470 \\ http://hal.grenoble-em.com/hal-01487470}

Submitted on 12 Mar 2017

HAL is a multi-disciplinary open access archive for the deposit and dissemination of scientific research documents, whether they are published or not. The documents may come from teaching and research institutions in France or abroad, or from public or private research centers.
L'archive ouverte pluridisciplinaire HAL, est destinée au dépôt et à la diffusion de documents scientifiques de niveau recherche, publiés ou non, émanant des établissements d'enseignement et de recherche français ou étrangers, des laboratoires publics ou privés. 
Cite as:" Bodas Freitas, I.M, Claussen, T., Fontana, R. and Verspagen, B. (2011).

Formal and informal external linkages and firms' innovative strategy. A cross-country comparison. Journal of Evolutionary Economics, 21 (1), 91-119."

\title{
Formal and informal external linkages and firms' innovative strategies. A cross-country comparison
}

\author{
Isabel Maria Bodas Freitas*, Tommy Clausen**, Roberto Fontana**, Bart Verspagen ${ }^{* * *}$
}

\begin{abstract}
Firms increasingly rely upon external actors for their innovation process. Interaction with these actors may occur formally (i.e. through a collaboration agreement) or informally (i.e. external actors acts as sources of information). We analyze the reasons why firms consider it to be important to develop formal and informal external linkages in the innovation process by looking at the role played by firms' innovative strategies and by taking into account the possibility that a complementarity or substitutive relationship might exist between formal and informal linkages. Data are from the Third Community Innovation Survey (CIS 3), where we have access to firm level micro-data from Sweden, Norway, the Netherlands and the UK.
\end{abstract}

Keywords: External information sources, Innovation strategy, Formal cooperation, Multivariate Probit

JEL codes: O31, O33, O38

Acknowledgements: A previous version of this paper has been presented at the $12^{\text {th }}$ International J. A. Schumpeter Society Conference in Rio de Janeiro. We thank the participants for the useful comments received. We also thank the editors of the special issue and two anonymous referees for their comments on previous drafts of the paper. The usual disclaimers apply.

\footnotetext{
* Corresponding author: Grenoble Ecole de Management, 12 rue Pierre Sémard-BP 127, 38003 Grenoble cedex 01 and DISPEA, Politecnico di Torino, Corso Duca degli Abruzzi, 24b, 10129 Torino.

Email: Isabel-Maria.Bodas-Freitas@grenoble-em.com

** University of Oslo and Nordland Research Institute, Norway, N-8049 Bodo.

Email: tommy.clausen@nforsk.no

*** Department of Economics, University of Pavia, Via San Felice 5, 27100, Pavia and KITeS, Bocconi

University, Via Sarfatti 25, 20139; Email: roberto.fontana@unibocconi.it

**** Department of Economics, Maastricht University, PO Box 616, 6200 MD Maastricht and UNU-Merit;

Email: b.verspagen@maastrichtuniversity.nl
} 


\section{Introduction}

Recent theoretical and empirical contributions in the literature on innovation have highlighted the importance of establishing external linkages to improve the innovation potential of firms. Theoretical papers have argued that external actors represent important sources of information for innovation and thus a positive relationship between the extent of reliance upon external linkages and firm R\&D performance should exist (Chesbrough, 2003). Empirical research has instead looked at the nature of the linkages distinguishing between the role played by specific actors such as suppliers, customers (von Hippel, 1988), and universities (Cohen et al., 2002; Laursen and Salter, 2004) as sources of information or as partners in formal linkages such as technological agreements and R\&D joint ventures (Freeman, 1991; Hagedoorn, 2002). However, the analysis of the role played by external linkages in the innovation process goes beyond the acknowledgement of their impact on firm performance and/or their nature and entails several aspects not all equally well explored in the existing literature.

The first aspect relates to the determinants of the choice of setting up external linkages. Although firms' reliance upon external linkages depends on internal research capabilities as well as on innovative investments (Cabagnols and Le Bas, 2002), a relatively neglected aspect is the issue of what drives firms' selection of which actors to interact with both formally and/or informally. In this respect, it is important to understand whether or not the choice is specific to firms' innovation strategies (i.e. doing product or process innovation). Recent contributions (Srholec and Verspagen, 2008) suggest that significant differences exist with regard to firms' innovative strategies and highlight how interacting with different actors contributes to the definition of these strategies. The first aim of this paper is to understand whether and to what extent firms' reliance upon external linkages is influenced by their innovation strategies. By focusing on two types of external linkages - informal linkages (i.e. when actors are a source of information for innovation) and formal linkages (i.e. when actors are formal partners in R\&D projects) - we will look at whether specific innovation strategies lead to interact with specific actors.

The second aspect concerns the choice of an 'appropriate mix' of formal and informal external linkages. Given the complexity of innovative activity, we should expect firms 
to draw upon several information sources and/or to combine formal and informal interactions. However, in the literature, linkages have generally been examined in isolation (the notable exception being Laursen and Salter, 2006) or separately from formal partnerships (Bönte and Keilbach, 2005, being the exception in this case), which provides a rather simple view of the innovation process. As a consequence, we know little about whether or not firms use linkages and information from different sources in a certain combination to carry out a specific innovative outcome. A better understanding of the role of external linkages in the innovation process should therefore result from taking into account the possibility that firms may simultaneously use many information sources as 'inputs' and also cooperate with several actors to carry out their innovative projects.

This perspective opens up the possibility that complementarity or substitution relationships exist between different actors. Indeed, prior research has found a significant relation between reliance on external information sources and the decision to engage in formal cooperative R\&D agreements (Cassiman and Veugelers, 2002). However, these researches have not examined the issue of substitution versus complementarity in a context in which firms can decide to use several external sources and at the same time cooperate with several actors. In this paper, we will look at the extent to what the use of formal and informal external linkages characterized by complementarity or substitution. It should be noted that we will control for firm level differences in innovation strategies, and examine complementarity and substitution relationships between informal and formal information sources.

The third aspect concerns whether firms' reliance upon external linkages in the innovation process could be specific to the institutional and/or industrial context in which they operate. Indeed, the literature on both national (Nelson, 1993) and sectoral (Malerba, 2004) systems of innovation stresses the notion that the institutional context shapes the pattern of innovation at the firm level. However, very few studies analyze whether national differences in the institutional and economic structures lead to systematic differences in the use of external partners, both as sources of information for innovation and as partners for collaboration. By considering four countries with different institutional organizations and market structures, we explore to what extent 
reliance upon formal and informal linkages is consistent across countries or whether systematic differences exist.

To address the aspects described above, we employ data from the Community Innovation Survey (CIS 3). The sample consists of firms that have innovated during the period 1998-2000 in four European countries: the Netherlands, Norway, Sweden and the UK. We consider the impact of the innovative strategies of firms on their reliance upon several external actors (viz. other enterprises of the group, suppliers, customers, competitors, universities, governmental institutes) as sources of information for innovation and as partners for innovation development. To account for the possibility that firms rely simultaneously upon several partnerships and sources as 'inputs' to the innovation process, a Multivariate Probit analysis is carried out for each country separately and then compared. The paper shows that firms with different innovative strategies rely upon different portfolios of formal or informal sources of information. At the national level, we find that innovative strategies seem to be more important for establishing formal links, while reliance on informal information sources varies across countries and industries, consistent with the view that national and industrial contexts shape the uses of information sources.

The paper is organized as follow. Section 2 reviews the literature on the role of formal and informal linkages for the firms' innovative activities. In Section 3, we describe the data and the methodology. Section 4 presents the results. Section 5 concludes this study.

\section{Background literature}

Innovative activity does not take place in a business world in which firms are isolated from each other and from other organizations. Both institutional and technological contexts shape the organizational context in which innovation occurs (Whitely, 2000). Indeed, industrial innovation can be understood as a process that involves search for information and interaction with both market based actors (i.e. customers, suppliers, competitors) and research institutions (i.e. universities and government) (Etzkowitz, 1998; Salter and Martin, 2001). These interactions may be the consequence of formal alliances and/or cooperation agreements or they may occur in a more informal way. In both cases, they usually entail some form of knowledge and/or information exchange 
between the partners involved. Information acquired from external linkages differs in the form of access (i.e. informal or formal) as well as on the content being transferred (Swann, 2002; Monjon and Waelbroeck, 2003). In particular, informal use of sources is associated with the internal capabilities of firms to access and to absorb the information produced by other market or research organizations immediately. Instead, the knowledge derived from formal collaborations is associated with the use of ideas and developments resulting from access to infrastructures, human capital, and innovative capabilities of partners.

Concerning the content, the capability to translate external information inputs into successful innovations has been traditionally associated with the presence of high absorptive capacity at the firm level (Cohen and Levinthal, 1989; Cohen et al., 2002). However, high absorptive capacity can be considered just a prerequisite. The development of a specific type of innovation is not accidental, but reflects the innovative strategies of firms (Swann, 2002; Tether, 2002). The capabilities required to innovate successfully vary depending on the type of innovation that firms want to develop. As a consequence, firms may choose to interact with specific actors in order to introduce specific innovations.

User-producer interaction, for instance, is widely acknowledged as crucial for carrying out product innovation (von Hippel, 1988). To develop and to market a novel product, getting knowledge and collaborating with customers is as important as performing internal R\&D investments, since customers are an important source of information that may boost product innovation (Levin and Reiss, 1988; Belderbos et al., 2004). When product innovation is based on a recent scientific discovery, it often entails a formal collaboration with universities (Beise and Stahl, 1999; Tether, 2002; Monjon and Waelbroeck, 2003). Firms that mainly pursue an imitation strategy instead seem to prefer horizontal technological information from competitors (Baldwin at al., 2002; Cabagnols and Le Bas, 2002). Firms pursuing process innovation, which entails investments in machinery and equipment, seem to require mainly interaction with suppliers (Pavitt, 1984; Malerba, 1992). Swann (2002) finds that British process innovators tend to use universities both as a source of information and as R\&D partners when compared to product innovators. Reichstein and Salter (2006) further find that knowledge from suppliers enhances process innovations in firms with a cost- 
focus strategy, while the probability of doing process innovation is negatively associated with the use of customers as a source of knowledge.

Acknowledging the presence of a positive correlation between establishing one specific linkage and pursuing a specific innovation is just one part of the whole picture. Innovation is a complex phenomenon and typically firms tap several sources of information at the same time. In their investigation of innovative strategies for a sample of European firms based on the CIS survey Shrolec and Verspagen (2008) have identified the presence of three possible approaches toward the use of external sources: a 'science based' approach, which combines reliance upon both universities and research institutes; a 'client and industry based' approach, which combines information from customers, competitors and other firms of the same group; and a 'supplier based' approach, which mainly relies upon information from suppliers. Each of these approaches is then linked in one or more types of innovation, with 'science based' firms participating more to joint projects with external organizations, 'client and industry based' firms doing more product innovation and 'supplier based' firms relatively more involved in the acquisition of machinery and equipment.

Complementarity may even exist between formal and informal linkages as reliance upon several informal sources can also occur in combination with the establishment of formal partnerships for innovation, in particular, the intensive use of external sources of information seems to enhance cooperation with public research organizations (Cassiman and Veugelers, 2002; Van Beers et al., 2008), or with external actors that are already considered to be an important source of knowledge for innovation (Belderbos et al., 2004).

Finally, besides being related to specific innovation strategies, the need to develop specific external linkages may also depend on the type of industry and technology (Pavitt, 1984; Marsili, 2001). Firms active in science-based industries generally tend to benefit most from interactions with public research organizations and focus on (novel) product innovation (Cabagnols and Le Bas, 2002). In technological complex and uncertain environments, informal interaction is also considered to be beneficial, even in intermediate and mature industry stages (Pyka, 2000). In supplier-dominated industries, firms rely mainly on suppliers as source of process-innovations (Leiponen, 
2002). Specialized-suppliers rely mainly on customers as sources of information to develop customized product-innovation and to solve technological problems for their clients (Riggs and von Hippel, 1994). In scale-intensive activities, which are also highcapital-intensive, firms achieve competitive advantage by exploiting economies of scale, and firms tend to innovate more in product than in process (Martínez-Ros and Labeaga, 2002).

Altogether, existing contributions hint at the following. When innovating is complex, firms require the integration of several specific types of knowledge and therefore they need to interact with several actors at the same time. On the one hand, the need to interact might be the consequence of the presence of a relationship of complementarity or substitution between several information sources. In other words, different information sources reinforce each other (i.e. complementarity) or firms tap different sources to acquire information that is difficult to access such as, for example, information possessed by competitors (i.e. substitution). On the other hand, interaction with several actors might be the consequence of the fact that firms may do several types of innovation which differ in terms of novelty and integration of market and production. In other words, firms pursue different 'innovation strategies'. In this paper, we analyze both the impact of different innovation strategies on the use of formal and informal information sources, as well as the complementarity and substitution relationship among the sources.

\section{Method and data}

The discussion in the previous section has highlighted the presence of a relationship between firms' innovative strategies and reliance upon external linkages. A key objective in this paper is then to analyze whether different innovation strategies go together with the use of informal and formal information sources. ${ }^{1}$ We have, in addition, stressed that firms seem to rely upon several external linkages at the same time. In the analysis we will therefore examine whether a substitution or complementarity relationship exists between informal and formal sources, and within

\footnotetext{
${ }^{1}$ A brief note on terminology is in order here. CIS questionnaires ask about 'innovation cooperation' and 'information sources' not about formal or informal sources. Throughout the paper we term as 'formal' those linkages with external actors that result from cooperation and 'informal' those that involved exchange of information not based on cooperation.
} 
each type of source. Our analysis is done separately for each country, following a system of simultaneous equations:

$$
\left\{\begin{array}{l}
\operatorname{Pr}\left(\operatorname{Inf}_{i j}\right)=f_{i}\left(\sum_{k \neq j} \operatorname{Inf}_{k j}, \sum_{k} \text { For }_{k j}, X_{i}\right) \\
\operatorname{Pr}\left(\text { For }_{i j}\right)=f_{i}\left(\sum_{k} \operatorname{Inf}_{k j}, \sum_{k \neq j} \text { For }_{k j}, X_{i}\right)
\end{array}\right.
$$

where $P r$ indicates the probability that a (formal or informal) source is used by the firm, Inf indicates informal information sources, For indicates formal cooperation linkages, $j$ subscripts for the actor relationships we identify (other enterprises part of the same group, suppliers, customers, competitors, universities, government research institutes), $\Sigma_{k}$ indicates a set including the elements subscripted by $k, X$ is a vector of explanatory variables, $i=1, \ldots, N$ indicates the individual firm, and $f$ indicates a function that we will approximate by the probit model. Thus, the model states that the probability for each (formal or informal) linkage is a function of the other linkages and a set of explanatory variables. For estimation purposes, we append an error term to each equation, and we allow these error terms to be correlated between the equations.

Our dependent variables are binary and have been constructed on the basis of two questions contained in the CIS 3 survey. Firms were asked to evaluate the importance of the sources of information used for technological innovation in the three years preceding the survey. We employ this question to identify the informal linkages (INF). ${ }^{2}$ The second question asked firms whether they had any co-operation arrangements on innovation activities with other enterprises or institutions during the same time period and to indicate the type of partner. We employ this question to identify the formal linkages (FOR). Among the several sources, we focus on those that appeared both as sources of information and as partners in R\&D (i.e. collaboration with consultants and in-house sources of information were excluded). Hence, we focus on Other enterprises within the group (INF_OTH, F_OTH), Suppliers (INF_SUP, FOR_SUP), Customers (INF_CUST, F_CUST), Competitors (INF_COMP, F_COMP), Universities or other higher

\footnotetext{
2 The question asked firms to evaluate the importance on a four item scale ('not used', 'low importance', 'medium importance', 'high importance'). Responses were recoded into a binary variable equal to zero if the source was not used or rated as having a low importance and equal to 1 if it was considered of medium or high importance.
} 
education institutes (INF_UNI, F_UNI), and Government research organizations (INF_GOV, F_GOV).

As explanatory variables, we use four sets of covariates. Our first set describes the innovation strategy of the firms. NEW_PDT is a dummy equal to one if the firm introduced a product that was new to the market (i.e. it is a 'novel innovator'). IMP_PDT is a dummy equal to one if the firm only introduced a product that was new to the firm (i.e. it is an imitator). Firms that declared to have introduced only process innovation are the reference category. PDT_PRC is a dummy equal to one if the firm introduced both a new product and a new process. Since we consider the introduction of specific innovation a proxy for firms' strategy, we treat the innovation types as independent variables that reflect firms' choices, rather than dependent variables that follow from other variables.

We expect that the development of innovations with certain characteristics, in terms of degree of product novelty and integration between process and product innovation, requires specific learning and R\&D efforts. Consequently, different innovation strategies are expected to rely on different external linkages to access specific information and knowledge to innovate. In particular, as suggested by our literature review, when compared to firms that make process innovations only, we expect 'novel product innovators' to rely more on formal and informal linkages with Customers, Universities and Governmental research institutes. Innovators with improved products instead should rely more on informal linkages with Customers and Competitors. Finally, we expect firms that made both product and process innovations to rely relatively more than 'only process innovators' on formal linkages with Suppliers and Customers, and more on formal and/or informal linkages with public research organizations.

Our second set of variables accounts for the fact that firms carry out different types of investments. Several studies have found that firms with different investment portfolios might develop different learning processes (Noteboom, 1999), forge different types of external linkages for innovating (Becker and Dietz, 2004) and engage in specific types of innovation. The variable INV_INT is the total share of innovative expenditures (i.e. expenditures in intramural, extra-mural $R \& D$, other knowledge, design and training) 
on the turnover of the firm. The variable INV_MAC is the share of total expenditures on machinery on the total turnover. ${ }^{3}$ INV_INT controls for the firm's efforts in building internal capabilities to improve internal efficiency and to respond to markets. INV_MAC controls for the impact of 'embodied innovation' on the probability to set up external linkages. To capture better the differentiation of innovative investment strategy of firms, we also created a variable INV_VAR that is a count variable of the different types of investment activities in which the firm has been involved. This variable varies between 0 and 5 .

To these variables we add a set of industry and firm level controls. It is widely acknowledged that firms in different industries seem to engage in diverse types of technical change and innovative activities, and focus on a variety of potential learning processes (Malerba, 1992). Thus, the specific industrial activity of firms might influence the reliance upon use of specific sources of information, both formal and informal. Firms are grouped into five categories of industries, according to the taxonomies proposed by Pavitt (1984) and Marsili (2001): fundamental process (FUND), complexproduct (COMPX), product-engineering (PDT_ENG), science-based (SCIE), and continuous process. ${ }^{4}$

Firm level controls include firm size and an indication of the largest market in which the firm operates. SIZE is measured as the logarithm of total the number of employees. Large firms, which invest highly in innovative activities, are expected to search more for information, to rely relatively more upon university research, and to cooperate relatively more with several actors to innovate (Cohen et al., 2002; Leiponen, 2002; Fontana et al., 2006). Finally, MKT is a dummy variable equal to one if the largest market of the firm is perceived to be international. The list of variables and their description is summarized in Table 1.

[Insert Table 1 about here]

\footnotetext{
${ }^{3}$ Investment strategies reflect the two factor loadings obtained when running a factor analysis on the intensity of expenditure in each innovative activity surveyed.

4 Fundamental-process activities include chemicals, plastic and rubber industries. Complex-products include transport equipment. Product-engineering include machinery and equipment industries. Sciencebased activities include represented pharmaceutical and electrical and optical industries. Continuousprocess includes all the other manufacturing activities. This is also the reference category.
} 
The estimation method is a Multivariate Probit maximum likelihood in which the decisions to engage in formal and informal linkages with a set of external organizations are estimated simultaneously. ${ }^{5}$ Formal or informal linkages data are binary but they have as many 'dimensions' as the number of external partner/ sources. The choices are not mutually exclusive. This method allows the simultaneous estimation of more than one binary probit equation with correlated disturbances. By allowing disturbances across equations to be freely correlated, the method allows to test for the correlation between dependent variables conditional on a certain number of common explanatory variables (Galia and Legros, 2004, p. 1193), thus providing insights into the extent of complementary of substitution between them. A positive (negative) correlation of the error terms between two equations is taken as an indication of complementarity (substitution) between the two dependent variables. ${ }^{6}$

\subsection{Data}

The data used in this paper come from the Community Innovation Survey 3 (CIS 3) that investigates the process of innovation development by firms in the period 19982000, in four European countries: The Netherlands, Norway, Sweden and the UK. The CIS survey asks firms about the type of innovation introduced in the three years preceding the survey, the sources of information they drew upon, their formal collaborative arrangements in order to innovate, as well as their expenditures and investments in several types of innovation activities. The process of innovation in services and in manufacturing has been found to be quite different (Miozzo and Soete, 2002; Savona et al., 2006). Therefore, the analysis undertaken in this paper focuses on manufacturing firms with more than nine employees. As the CIS survey does not collect data on the sources of information and collaborative arrangements for noninnovators, we cannot proceed, as we wished, with the analysis for the non-innovative firms. Thus all the firms in our sample are innovative in the sense that they have introduced at least one innovation in the period covered by the survey. Our sample includes a total of 3963 firms (1633 firms for The Netherlands, 1005 firms for the UK,

\footnotetext{
${ }^{5}$ More specifically, the estimation method employed here is based on the 'recursive conditioning simulator' implemented for STATA by Cappellari and Jenkins (2003).

${ }^{6}$ As a robustness check we have also performed for each country twelve separate Probit regressions one for each type of linkage. Results in terms of sign and significance of the estimators of multivariate and binary Probit are very similar. These results are available upon request from the corresponding author.
} 
559 for Sweden, and 766 for Norway). These firms have established at least 11,245 linkages with external actors between 1998 and 2000.7

The majority of linkages are established with customers ( $28.35 \%$ of the total), followed by suppliers $(24.15 \%)$, other firms of the same group (15.99\%), and competitors (15.46\%). Fewer linkages are established with universities (9.27\%) and governmental research institutions $(7.00 \%)$. The Netherlands is the country with the highest number of total established linkages; it accounts for slightly more than one third of the total. The UK follows with a share of $25.37 \%$. The two Scandinavian countries account for the remaining $41.15 \%$. It has to be noted that, in general, firms in our sample established more informal than formal linkages.

Statistically significant differences across countries are found in terms of the average number of linkages established by innovative firms. Firms in our sample established on average 2.84 linkages with different types of external actors. Swedish firms established the highest number of linkages on average (3.67) followed by Norwegian (3.39), British (2.84) and Dutch (2.31) firms. Swedish firms tended to establish the highest number of formal linkages on average (1.05), as well as the highest number of informal linkages on average (2.63).

Finally we look at the distribution of linkages by country and by innovation strategy. The majority of the linkages $(60.33 \%)$ were established by firms pursuing both product and process strategy. Firms that introduced improved products (i.e. a product that was new to the firm) followed with $14.92 \%$ of total linkages. The rest of the other linkages were distributed across firms that introduced novel products (i.e. a product that was new to the market) (13.68\%) and firms that introduced only process innovation $(11.07 \%)$. Figure 1 depicts the distribution of the linkages by innovation strategies across countries.

[Insert Figure 1 about here]

\footnotetext{
${ }^{7}$ CIS questionnaires provide information on whether or not a linkage with a specific partner is established. They do not provide information on the exact number of linkages. Thus, based on this information we can infer that at least 11,245 linkages have been established.
} 
Concerning Dutch firms, the majority of the linkages were established by firms doing both product and process innovation, followed by firms introducing new products (both novel and improved ones). The same applies to Norwegian firms. A slightly different pattern emerges for UK and Sweden. In the case of the UK, a large majority of linkages were established by firms doing process innovation only. In the case of Swedish firms, those introducing novel products showed the highest share of the total linkages followed closely by firm doing process innovation only.

All in all, our descriptive results point to the presence of some heterogeneity across countries concerning both the type of linkages (formal vs. informal) and the pattern of innovative strategies. In the remaining section of the paper we will look at the ways in which different innovation strategies impact on the choice of specific types of linkages. We will estimate the system of equations (1) for each of the four countries individually, and compare the results across countries. Then we analyze the estimated correlation matrices for the error terms in the equations in each country. Each matrix provides information on the complementary or substitutive relation between each type of linkages in the country. In the end, we will comment about cross-country similarities and difference.

\section{Informal and formal linkages and firms' innovative strategy}

Estimates (marginal effects) are reported in four separate tables (2 to 5), one for each country. ${ }^{8}$ For simplicity and for the purpose of cross country comparison, we will focus on the results for each set of explanatory variables across the tables.

[Insert Tables 2 - 5 about here]

\section{$\underline{\text { Results for innovative strategies }}$}

We start by looking at the relationship between firms' innovation strategies and reliance upon formal and informal linkages. Concerning novel product innovators (NEW_PDT), our results suggest that firms pursuing this strategy were relatively more

\footnotetext{
8 Restrictions concerning data accessibility from National Statistical Offices prevented us from pooling the data. This is the main reason why we are estimating four separate sets of regressions. The marginal effects reported refer to the single equation for which they are documented (i.e. they reflect the increase in probability of a positive outcome in the single equation that is the result of the direct effect of a change in the exogenous variable to which the marginal effect refers). The marginal effects are calculated as is usual in Probit models. The standard errors of the marginal effects are calculated using the estimated variancecovariance matrix of parameters in the single equation.
} 
likely than only process innovators (the reference category) to set up linkages with customers, and to a lesser extent with research organizations. This result holds across countries, although for Scandinavian firms only in the case of formal linkages. Swedish novel product innovators were also relatively more likely to engage in formal collaborations with competitors. Norwegian and Dutch novel product innovators also tended to rely upon (formal) collaborations with suppliers and other firms of the group.

Firms that introduced improved products (IMP_PDT) present a different profile. Still, customers are important for these firms (both as a source of information and as formal partners). However, our marginal effects show that other actors matter as well. British Dutch firms in this category tended to draw knowledge informally from competitors (the magnitude of the effect is the highest in the case of British firms) reflecting the importance of following an imitation strategy. 'Improved product innovators' were also less likely to tap informally into suppliers in the UK. Finally, Norwegian and Dutch firms that introduced improved products seemed relatively more likely to engage in formal collaboration with other enterprises of the group, in contrast to British firms.

Finally, we find heterogeneity in behavior for firms that introduced both a new product and a process (PDT_PRC). Again customers and public research organizations (governmental institutes in Norway and the UK, universities in Norway, Sweden, and the Netherlands) were important mainly as partners in formal collaborations. In the case of cooperation with customers, the effect seems to have been particularly strong for Sweden. Competitors were also an important source of information for all firms, except for British and Swedish product and process innovators. (Formal) interaction with suppliers was relevant for Dutch firms in this group and to a lesser extent for Swedish and Norwegian firms. Informal linkages with customers were important for product and process innovators in Norway and the Netherlands. In this case, a standard deviation increase around the mean increases the probability of tapping into customers of $16.6 \%$ and $12.3 \%$ for Norwegian and Dutch product and process innovators. 
Firms' investments are captured by three variables. In the case of innovative investment intensity (INV_INT), our marginal effects are generally positive suggesting a positive correlation with reliance upon some informal and formal external actors in each of the four countries. For instance, the greater the firms' expenditures in internal innovative capabilities, the more firms were able to interact (either formally or informally) with governmental institutes and universities particularly in the Scandinavian countries. The more firms invested in innovative activities, the more they interact with competitors in the Netherlands. Negative and significant coefficients were instead found for formal interactions with customers in UK, competitors in Norway and informal interactions with suppliers in Norway. When significant, marginal effects were generally low.

Concerning investment in machinery (INV_MAC), our results indicate that, in a few cases the share of total expenditures in machinery on the total turnover significantly increased the likelihood of engaging in formal linkages. When we look at informal relationships though, firms with a relatively higher share of investment in machinery were less likely to tap universities as source of information in The Netherlands. Higher investment in machinery relatively increases the likelihood of interacting with other enterprises of the group as well as with suppliers in the UK, in contrast to Norway. These results suggest that that in some countries (i.e. The Netherlands) information acquired from research organizations may substitute for investment in machinery. One explanation is that universities may allow firms to use specific equipment for their innovation.

Finally, marginal effects for investment variety (INV_VAR) were generally positive indicating that the more diversified the investment portfolio, the more likely firms were to rely upon external actors both as source of information (except for suppliers) and as cooperation partners. In this case, the magnitude of the marginal effect was higher than in the previous cases and similar across countries.

\section{$\underline{\text { Results for industry controls }}$}

When looking at the impact of industrial control variables, results reveal some similarities but also important cross country differences. 
Concerning firms pursuing science-based activities (SCIE), our marginal effects were positive and particularly strong for British and Norwegian firms setting up informal linkages with customers. Norwegian science-based firms were also less likely to collaborate with enterprises of the group. Dutch and British science-based firms tended to establish formal relationships with governmental research institutes. Dutch sciencebased firms were also more likely to use informal linkages with universities.

Consequently, science-based activities seemed to be more R\&D intensive and more dependent on public research in the Netherlands, and carried on in a more 'marketoriented' way in the UK and in Norway.

The picture appears more variegated in the case of complex-product firms (COMPX). In the UK and the Netherlands, these firms tapped customer information to innovate. In Sweden, by contrast, these firms set up relatively fewer formal collaborations with universities. Norwegian firms in complex-product activities were less likely to collaborate with other enterprises of the group, suppliers and clients. Dutch firms active in this sector seemed instead to collaborate with competitors. All in all, our results indicate that the nature of the activity of complex product firms is so different across the four countries that they need to integrate in different ways different bundles of knowledge, and also outsource different steps of the production process.

Concerning firms active in product-engineering industries (PDT_ENG) marginal effects were positive and relatively higher in the case of British firms that interacted informally with universities and suppliers, and with customers both in Norway, Sweden, and the Netherlands. Instead, firms relied less on informal linkages suppliers in the Netherlands, and less on informal linkages with public research organizations in Norway. Thus, product-engineering firms seemed to rely more on public research results in the UK, while they relied more on customer- relationships in the Netherlands and the Scandinavian countries.

Finally, our results suggest that British and Dutch firms active in fundamental-process activities (FDT) relied more than firms in continuous-process activities upon relationships with other enterprises of their group to innovate. We find the opposite for Norwegian firms. Swedish firms active in fundamental-process activities did not differ much on the reliance on informal linkages with firms in continuous-process activities. 
Fundamental-process activities seems to have presented a similar pattern of reliance upon external linkages across the four countries.

\section{$\underline{\text { Results for control variables }}$}

Results for the impact of control variables, capturing the organizational and market characteristics of firms, are quite consistent with previous results from the existing literature. In the four European countries analyzed, large firms were generally more likely than smaller ones to engage in formal collaborations as suggested by the positive and significant coefficient of SIZE. This relationship holds for any actor, except for supplier and customers in the UK, and for competitors in Norway. Moreover, the larger the firm, the higher is the probability of drawing upon informal sources of information from all actors, except for suppliers and customers.

Concerning the location of the largest market (MKT), firms whose largest market is international had a relatively higher propensity to interact with public research organization (universities) in Norway and UK and with customers (UK and Netherlands). Also imitating competitors seems to have been important for these firms especially in UK and Sweden.

\subsection{Complementarity and substitution among external linkages}

Our empirical method allows us to produce, from each estimate, a matrix of correlation coefficients of the error terms in the equations for each dependent variable. Looking at the sign of the coefficients provides an indication as to whether the external linkages are complementary (positive coefficient) or substitutes (negative coefficient) for the firms in the sample. In this section, we comment upon the relationships. Tables reporting the coefficients for each country separately are contained in the Appendix.

In all countries we do not find evidence of a significant relationship of substitution among any actor. Coefficients for formal linkages are generally significant and positive, thus complementarity exists between these external sources of information. In other words, firms that established formal collaborations tended to do so with more than one actor. Complementarity is also found for informal linkages with competitors, suppliers and customers and between informal linkages with competitors and informal linkages with governmental research institutes and universities, though to a lesser extent. This 
result suggests that interactions with competitors may be more efficient if combined with interactions with public research organizations.

Complementarity is stronger in the case of formal collaborations, and weaker in the case of informal linkages especially with customers and competitors. In Norway, we also find strong complementarity between formal and informal linkages with other enterprises of the group and formal collaboration with universities.

Consistently with previous findings (Belderbos et al., 2004), firms in our sample tended to collaborate with actors that they also used as sources of information. However, in our case complementarity between formal and informal linkages with the same actor was generally weak except for interactions involving governmental research institutes and universities. In Norway, formal and informal linkages with competitors were not significantly complementary.

Interestingly, linkages with research organizations tended to exhibit the highest number of significant complementarities, reflecting the notion that firms relied upon information from research organizations to improve their access to an even wider pool of sources. The Netherlands is the country in which we found the highest number of complementarities among all types of external linkages, except for informal linkages with other enterprises of the group and government research institutes, as well as for collaboration with customers and competitors. Norway instead had the smallest number of significant correlations, followed by Sweden. In particular, in Sweden, the number of complementarities was the smallest for interactions among universities and governmental research institutes and other informal sources. In Norway, the number of complementarities was the smallest for informal interactions with suppliers and Customers. These results suggest that Norwegian and Swedish firms were eventually more able to absorb external information from informal interactions without the need to collaborate with these actors or access other sources. Dutch and British firms instead needed to use a wider mix of external sources and strategies to innovate effectively.

\subsection{Highlighting cross-country similarities and differences}

The final step of our analysis involves the identification of cross-country similarities and/or differences in the determinants of the choice of formal and informal external 
linkages. To achieve this goal, we decided to synthesise our previous results in two separate tables, one summarizing results for formal linkages and the other the informal linkages. In order to keep our exposition clear, we only focus on whether or not a specific variable was found significant in the previous analysis. Thus, the signs in each table correspond to the countries in which each coefficient was found to be significantly different from zero.

Table 6 below reports the results for the subset of formal linkages.

[Insert Table 6 about here]

The emerging evidence in this case points to cross country similarity although some dissimilarities exist at the firm level. For instance, in almost every country the larger the firm size, the higher the probability of cooperation. Similarly, the more varied the firm investment portfolio, the higher the probability of cooperation.

Concerning the impact of innovation strategy, our results suggest that, in every country, firm cooperation with customers was the outcome of an innovative strategy involving novel product introduction. Similarly, a strategy based on novel product introduction was always pursued by firms cooperating with universities or governmental research institutes. Both results are consistent with previous findings (Beise and Stahl, 1999; Tether, 2002) discussed in Section 2. In terms of investment, some similarities at the firm level can be found, too. In three countries out of four, the share of innovative expenditures was positively and significantly associated to the probability of cooperating with other firms of the same group, universities, and governmental research institutes. Few similarities are found instead concerning the impact of investments in machinery as well as concerning industry specific effect.

Our results for the subset of informal linkages are instead reported in Table 7.

[Insert Table 7 about here]

In this case, the evidence is more mixed. Again, firm size and investment variety are, when significant, always positively associated to the probability of relying upon any 
external source of information. The biggest difference with respect to the previous results concerns the role of both innovative strategies and investment. In these cases, our results suggest the following. First, correlation is weaker when compared to the case of formal interactions since relatively fewer coefficients turn out to be significantly different from zero. Second, in those cases in which correlation is significant, there is no single strategy which can be pursued to tap any source of information. On the contrary, tapping each information source seems to require the implementation of a different mix of strategies. Third, the implementation of a specific mix is mainly country specific, as no strategy (or mix of) exists that is common to every country (as it happened with novel product introduction in the case of formal linkages).

All in all, the previous considerations point to the following conclusions. No clear cut pattern seem to emerge concerning the relative importance of firm specific effect vis-àvis country effects in the establishment of formal and informal external linkages. However, the establishment of formal linkages seems to be the consequence of firm specific characteristics especially related to innovation strategies, and, to a lesser extent, investment, rather than of country specific characteristics. This finding is consistent with the results of Shrolec and Verspagen (2008), who pointed to the role of firms strategies in explaining pattern of innovation rather than sectoral and national factors. The establishment of informal linkages instead seems to depend relatively less on firm characteristics. In this case, differences across national and sectoral innovation systems are so strong that differences still remain even after controlling for firm strategies and other characteristics.

\section{Conclusions}

This paper has started from the observation that firms tend to rely upon the contribution of different external actors in their innovation process. This empirical fact may either be due to the presence of a relationship of complementarity or substitution between several information sources or a consequence of the fact that firms undertake several types of innovations that differ in terms of novelty and integration of market and production (i.e. firms have different innovation strategies). In this paper, we have empirically analyzed both these possibilities using a sample of innovating firms from four European countries (Norway, Sweden, the Netherlands and the UK). 
Concerning the complementarity/ substitutability issue, our estimation approach allowed us to account for the simultaneous use of several external linkages. In this respect, our results suggest that few cross-countries differences exist and that there are no substitution relations across different external actors. In other words, in all the countries in our sample firms tend to cooperate formally with actors that they also use to screen on the market. This result confirms previous findings in the literature (Belderbos et al., 2004), though in our case complementarity between formal and informal linkages with the same actor seems weak.

Concerning the role of different innovation strategies, our results have shown that firms with different innovation strategies tend to rely on different mixes of external actors and that some differences exist across countries. In particular, novel product innovators tend to have formal and informal interaction with customers and with research organizations to a lesser extent. Firms that introduce only improved products seem to regard informal linkages with competitors (both formal and informal) and with customers as more important in the innovation process. In comparison, firms that innovate in both product and process tend to rely relatively more on customers and public research organizations. We have also found differences in the portfolio of external linkages across firms active in different industrial and technological contexts. At the national level, our analysis points to the important role played by firm characteristics and innovative strategies particularly in the establishment of formal linkages with external actors. In the case of informal linkages firms specific characteristics tend to matter less.

All in all, our results provide novel insights into the role of firms' innovative strategies in establishing external linkages in different sectoral as well as national contexts. These results, although preliminary and in need of further corroboration, suggest some managerial and policy implications. On the managerial side, if firms' capabilities to use certain types of linkages and the adequacy of knowledge provided by external actors differ across countries and sectors, then the decision to enter into new markets (internationalization, delocalization or diversification) may create problems of identification, access and process of external sources of information. Therefore, firms may need to complement these decisions with investment in wider search and collaborative activities, as well as in new routines for enhancing the processing of 
external information. On the policy side, our results suggest not only that public research organizations in different countries have different capabilities to provide specific relevant innovative knowledge, but also that their capabilities depend on the quality and function of the interaction among different market actors. It should be the task of policy makers to nurture and to reinforce these interactions. 


\section{REFERENCES}

Baldwin J., Hanel P. and D. Sabourin, 2002. Determinants of Innovative Activity in Canadian Manufacturing Firms, in A. Kleinknecht and P. Mohnen (eds), Innovation and Firm Performance. Palgrave: London.

Becker, W. and J. Dietz, 2004. R\&D Cooperation and Innovation Activities of Firms. Evidence for the German Manufacturing Industry. Research Policy 33, 209-223.

Beise, M. and H. Stahl, 1999. Public research and industrial innovations in Germany. Research Policy 28, 397-422.

Belderbos, R., M. Carree, and B. Lokshin, 2004. Cooperative R\&D and firm performance. Research Policy 33: 1477-1492.

Belderbos, R., M. Carree, B. Lokshin and R. Veugelers, 2004. Heterogeneity in R\&D cooperation strategies. International Journal of Industrial Organization 22: 1237-1263

Bönte, W. and M. Keilbach, 2005. Concubinage or marriage? Informal and formal cooperations for innovation. International Journal of Industrial Organization, 23: 279302.

Cabagnols, A. and C. Le Bas, 2002. Differences in the Determinants of Product and process Innovations: The French Case, in A. Kleinknecht and P. Mohnen (eds), Innovation and Firm Performance. Palgrave: London.

Cainelli, G., R. Evangelista, and M. Savona, 2006. Innovation and economic performance in services: a firm-level analysis. Cambridge Journal of Economics 30, 435 458Cappellari, L. and S.P. Jenkins, (2003). Multivariate Probit Regressions using Simulated Maximum Likelihood. The STATA Journal, 3: 278-294.

Cassiman, B. and R. Veugelers, 2002. Spillovers and R\&D cooperation: some empirical evidence. American Economic Review 92(4): 1169-1184.

Chesbrough, H., 2003. Open Innovation. Harvard University Press: Cambridge, MA.

Cohen W.M., Levinthal D.A., 1989. Innovation and learning: the two faces of R\&D. Economic Journal 99: (September): 569-596.

Cohen, W.M.; R.R. Nelson and J.P. Walsh, 2002. Links and impacts: the influence of public research on industrial R\&D. Management Science 48(1): 1-23.

Duranton, G., 2000. Cumulative Investment and Spillovers in the Formation of Technological Landscapes. The Journal of Industrial Economics 48 (2), 205-213 
Fontana, R., A. Geuna, and M. Matt, 2006. Factors affecting university-industry R\&D projects: The importance of searching, screening and signalling. Research Policy 35, 309-323.

Freeman C., 1991. Networks of innovators: A synthesis of research issues. Research Policy 20, 499-514.

Galia, F. and D. Legros, 2004. Complementarities between obstacles to innovation: evidence from France. Research Policy 33, 1185-1199.

Hagedoorn J. 2002. Inter-firm R\&D partnerships: an overview of major trends and patterns since 1960. Research Policy 31: 477-492

Laursen, K. and A. Salter, 2004. Searching high and low: what types of firm use universities as a source of innovation? Research Policy 33: 1201-1215.

Laursen, K. and A. Salter, 2006. Open for innovation: the role of openness in explaining innovation performance among UK manufacturing firms. Strategic Management Journal 27: 131-150.

Leiponen, A., 2002. Why do firms not collaborate? The role of competencies and Technological Regimes, in A. Kleinknecht and P. Mohnen (eds), Innovation and Firm Performance. Palgrave: London.

Levin, R.C. and P. C. Reiss, 1988. Cost-Reducing and Demand-Creating R\&D with Spillovers. The Rand Journal of Economics 19 (4), 538-556

Malerba, F., 1992. Learning by firms and incremental technical change. The Economic Journal, 102, 845-859.

Malerba, F. (2002). Sectoral systems of innovation and production. Research Policy 31, 247-264

Marsili, O., 2001. The Anatomy and Evolution of Industries: Technological Change and Industrial Dynamics. Edward Elgar, Cheltenham, UK and Northampton, MA.

Martínez-Ros E. and J. M. Labeaga, 2002. Modelling Innovation Activities Using Discrete choice Panel Data Models, in A. Kleinknecht and P. Mohnen (eds), Innovation and Firm Performance. Palgrave: London.

Miozzo, M. and L. Soete, 2001. Internationalization of Services: A Technological Perspective. Technological Forecasting and Social Change, vol. 67, no. 2-3, 159-185.

Monjon, S. and P. Waelbroeck, 2003. Assessing spillovers from universities to firms: evidence from French firm-level data. International Journal of Industrial Organization 21, 1255-1270. 
Nelson, R. R., 1993. National Innovation Systems: A Comparative Analysis. Oxford Univesity Press, New York.

Noteboom, B., 1999. Innovation and inter-firm linkages: new implications for policy. Research Policy, 28, 793-805.

Pavitt, K., 1984. Sectoral patterns of technical change: towards a taxonomy and a theory. Research Policy 13(6), 343-373

Pyka, A., 2000. Informal Networking and Industrial Life Cycles, Technovation, 20, 25-35

Reinchstein, T. and A. Salter, 2006. Investigating the sources of process innovation among UK manufacturing firms. Industrial and Corporate Change 15(4), 653-682

Riggs, W. and E. von Hippel, 1994. Incentives to innovate and the sources of innovation: the case of scientific instruments. Research Policy 23, 459-469

Shrolec, M. and B. Verspagen, 2008. The Voyage of the Beagle in Innovation Systems Land. Explorations on Sectors, Innovation, Heterogeneity and Selection. No 20080220, Working Papers on Innovation Studies from Centre for Technology, Innovation and Culture, University of Oslo.

Swann G. M. P., 2002. Innovative Businesses and the Science and Technology Base: An Analysis Using CIS3, Data Report for Department of Trade and Industry, Manchester Business School University of Manchester.

Tether, B., 2002. Who co-operates for innovation, and why: an empirical analysis. Research Policy 31: 947-967.

von Hippel, E., 1988. The Sources of Innovation. Oxford University Press: New York. Whitley, R., 2000. The institutional structuring of innovation strategies: business systems, firm types and patterns of technical change in different market economies. Organization Studies 21, 855-886. 
LIST OF TABLES

Table 1: Variable description

\begin{tabular}{|c|c|c|}
\hline & Variable Name & Description \\
\hline & \multicolumn{2}{|l|}{ "Dependent variables } \\
\hline & INF_OT & $\begin{array}{l}\text { Rated as medium or highly important Other } \\
\text { Enterprises of the same group as source of } \\
\text { information to innovate }\end{array}$ \\
\hline & INF_SUP & $\begin{array}{l}\text { Rated as medium or highly important Suppliers } \\
\text { as source of information to innovate }\end{array}$ \\
\hline & INF_CUST & $\begin{array}{l}\text { Rated as medium or highly important Customers } \\
\text { as source of information to innovate }\end{array}$ \\
\hline & \multirow{2}{*}{ INF_COMP } & Rated as medium or highly important \\
\hline & & Competitors as source of information to innovate \\
\hline & \multirow{2}{*}{ INF_UNI } & Rated as medium or highly important \\
\hline & & $\begin{array}{l}\text { Universities as source of information to innovate } \\
\text { Rated as medium or highly important }\end{array}$ \\
\hline & INF_GOV & $\begin{array}{l}\text { Governmental research institutes as source of } \\
\text { information to innovate }\end{array}$ \\
\hline & F_OT & $\begin{array}{l}\text { Did a co-operation arrangement with Other } \\
\text { enterprises of the same group }\end{array}$ \\
\hline & F_SUP & Did a co-operation arrangement with Suppliers \\
\hline & F_CUST. & Did a co-operation arrangement with Customers \\
\hline & F_COMP & Did a co-operation arrangement with Competitors \\
\hline & F_UNI. & Did a co-operation arrangement with Universities \\
\hline & \multirow{2}{*}{ F_GOV } & Did a co-operation arrangement with \\
\hline & & Governmental research institutes \\
\hline & \multicolumn{2}{|l|}{ Explanatory variables } \\
\hline \multirow{3}{*}{$\begin{array}{l}\text { INNOVATION } \\
\text { STRATEGY }\end{array}$} & NEW_PDT & $\begin{array}{l}\text { The firm introduced a product that was new to } \\
\text { the market }\end{array}$ \\
\hline & IMP_PDT & The firm introduced only a product that was new \\
\hline & PDT_PRC & $\begin{array}{l}\text { The firm introduced both a product and a process } \\
\text { innovation }\end{array}$ \\
\hline \multirow{3}{*}{ INVESTMENT TYPE } & INV_INT & $\begin{array}{l}\text { Total share of innovative expenditures (i.e. } \\
\text { expenditures in intramural, extra-mural R\&D, } \\
\text { other knowledge, design and training) on the } \\
\text { turnover }\end{array}$ \\
\hline & INV_MAC & $\begin{array}{l}\text { Share of total investment in machinery on the } \\
\text { total turnover }\end{array}$ \\
\hline & INV_VAR & $\begin{array}{l}\text { Count of the different types of investment } \\
\text { activities the firm has been involved in (Max } 5 \text { - } \\
\text { Min 0) }\end{array}$ \\
\hline \multirow{4}{*}{ INDUSTRY CONTROLS } & FDT & Fundamental process firm \\
\hline & COMPX & Complex-product firm \\
\hline & PDT_ENG & Product-engineering firm \\
\hline & SCIE & Science-based firm \\
\hline \multirow{2}{*}{ FIRM CONTROLS } & SIZE & Logarithm of the total number of employees \\
\hline & MKT & Firm's largest market is international \\
\hline
\end{tabular}


Table 2: Multivariate Probit estimations (marginal effects) of reliance upon formal and informal external linkages. Results for Sweden.

\begin{tabular}{|c|c|c|c|c|c|c|c|c|c|c|c|c|}
\hline & INF_OT & INF_SUP & INF_CUST & INF_COMP & INF_UNI & INF_GOV & F_OT & F_SUP & F_CUST & F_COMP & F_UNI & F_GOV \\
\hline \multirow[t]{2}{*}{ NEW_PDT } & -0.0006 & -0.0293 & & -0.0 & 40 & & & & & 8 & 872 & \\
\hline & 0.0503 & 0.0503 & 0.0336 & 0.0503 & 0.0415 & 0.0324 & $0.0323 *$ & 0.0407 & $0.0403^{* * *}$ & $0.0226 * *$ & $0.0381^{* *}$ & $0.0260 *$ \\
\hline \multirow[t]{2}{*}{ IMP_PDT } & 0.1131 & 0.0187 & 0.0570 & 0.0002 & -0.0819 & 0.0018 & 0.0117 & -0.0199 & 0.0970 & 0.0202 & 0.0034 & 0.0165 \\
\hline & $0.0665^{*}$ & 0.0631 & $0.0339 *$ & 0.0643 & 0.0498 * & 0.0437 & 0.0459 & 0.0549 & 0.0636 & 0.0346 & 0.0539 & 0.0398 \\
\hline \multirow[t]{2}{*}{ PDT_PRC } & 0.0517 & 0.0263 & 0.0207 & -0.0488 & 0.0154 & 0.0082 & 0.0164 & 0.0751 & 0.1268 & 0.0186 & 0.0772 & 0.0248 \\
\hline & 0.0510 & 0.0502 & 0.0340 & 0.0506 & 0.0428 & 0.0333 & 0.0317 & 0.0421 * & $0.0415^{* * *}$ & 0.0193 & $0.0388^{* *}$ & 0.0260 \\
\hline \multirow[t]{2}{*}{ INV_INT } & -0.0027 & -0.0069 & 0.0124 & -0.0003 & 0.0051 & 21 & 0.0042 & 63 & 0.0013 & 11 & 0.0074 & 0.0037 \\
\hline & 0.0033 & $0.0035^{* *}$ & $0.0053^{* *}$ & 0.0031 & $0.0025^{* *}$ & 0.0019 & $0.0017^{* *}$ & $0.0025^{* *}$ & 0.0027 & 0.0009 & $0.0022^{* * *}$ & $* 0.0015^{* *}$ \\
\hline \multirow[t]{2}{*}{ INV_MAC } & -0.0016 & 0.0129 & 0.0016 & 0.0030 & -0.0015 & -0.0031 & 0.0007 & 0.0006 & 0.0047 & 0.0016 & -0.0111 & -0.0031 \\
\hline & 0.0075 & 0.0085 & 0.0038 & 0.0047 & 0.0059 & 0.0058 & 0.0046 & 0.0060 & 0.0036 & 0.0010 & 0.0093 & 0.0052 \\
\hline \multirow[t]{2}{*}{ INV_VAR } & 0.0184 & 0.0371 & 0.0264 & 0.0271 & 0.0256 & 0.0173 & 0.0236 & 0.0525 & 0.0408 & 0.0037 & 0.0483 & 0.0208 \\
\hline & 0.0127 & $0.0131^{* * *}$ & $0.0099 * * *$ & $0.0130^{* *}$ & $0.0107^{* *}$ & $0.0080 * *$ & $0.0076^{* * *}$ & $0.0102 * * *$ & $0.0098^{* * *}$ & 0.0040 & $0.0092 * * *$ & $* 0.0060 * * *$ \\
\hline \multirow[t]{2}{*}{ SCIE } & 0.1069 & -0.0418 & 0.0097 & 0.1084 & -0.0530 & -0.0480 & -0.0406 & 0.0084 & -0.0086 & -0.0050 & 0.0186 & -0.0250 \\
\hline & $0.0603 *$ & 0.0592 & 0.0408 & $0.0592 *$ & 0.0468 & 0.0331 & 0.0303 & 0.0474 & 0.0457 & 0.0201 & 0.0436 & 0.0239 \\
\hline \multirow[t]{2}{*}{ COMPX } & 0.2099 & 0.0479 & -0.0167 & -0.1290 & -0.1879 & -0.1111 & -0.0606 & 0.1527 & 0.1014 & 0.1177 & -0.1350 & 0.0205 \\
\hline & $0.1054^{* *}$ & 0.1017 & 0.0730 & 0.0974 & $0.0379 * * *$ & $0.0272^{* * *}$ & 0.0372 & 0.1003 & 0.0898 & $0.0707^{*}$ & $0.0343^{* * *}$ & * 0.0530 \\
\hline \multirow[t]{2}{*}{ PDT_ENG } & 0.0034 & -0.1020 & 0.0922 & 0.1587 & 0.0175 & -0.0469 & -0.0596 & 0.0167 & 0.0303 & 0.0103 & 0.0222 & -0.0340 \\
\hline & 0.0689 & 0.0693 & $0.0361^{* *}$ & $0.0672 * *$ & 0.0571 & 0.0346 & $0.0298^{* *}$ & 0.0570 & 0.0552 & 0.0263 & 0.0521 & 0.0245 \\
\hline \multirow[t]{2}{*}{ FDT } & 0.1357 & -0.0452 & 0.0572 & -0.0438 & 0.0301 & 0.0078 & -0.0591 & 0.0453 & -0.0182 & 0.0397 & 0.0767 & -0.0333 \\
\hline & 0.0900 & 0.0868 & 0.0442 & 0.0831 & 0.0767 & 0.0569 & 0.0387 & 0.0760 & 0.0659 & 0.0431 & 0.0792 & 0.0354 \\
\hline \multirow[t]{2}{*}{ SIZE } & 0.1000 & 0.0201 & -0.0013 & 0.0281 & 0.0785 & 0.0455 & 0.0583 & 0.0293 & 0.0297 & 0.0111 & 0.0894 & 0.0403 \\
\hline & $0.0150^{* * *}$ & 0.0152 & 0.0107 & 0.0150 * & 0.0126 ** & $0.0093^{* * *}$ & $0.0095^{* * *}$ & $0.0121 * *$ & $0.0116^{* *}$ & $0.0047^{* *}$ & $0.0121 * * *$ & 0.0078 \\
\hline \multirow[t]{2}{*}{ МKT } & 0.0430 & -0.0946 & 0.1145 & 0.1087 & -0.0300 & -0.0352 & 0.0209 & -0.0206 & -0.0058 & -0.0049 & 0.0157 & 0.0084 \\
\hline & 0.0456 & $0.0463^{* *}$ & $0.0325^{* * *}$ & $0.0462 * *$ & 0.0398 & 0.0306 & 0.0286 & 0.0380 & 0.0366 & 0.0155 & 0.0341 & 0.0228 \\
\hline
\end{tabular}

Obs: 559

Wald Chisq: $533.40^{* * *}$

Log Likelihood: -2620.06

Note: ${ }^{* * *}$ significant at $1 \%$; ** significant at $5 \%,{ }^{*}$ significant at $10 \%$ 
Table 3: Multivariate Probit estimations (marginal effects) of reliance upon formal and informal external linkages. Results for Norway.

\begin{tabular}{|c|c|c|c|c|c|c|c|c|c|c|c|c|}
\hline & INF_OT & INF_SUP & INF_CUST & INF_COMP & INF_UNI & INF_GOV & F_OT & F_SUP & F_CUST & F_COMP & F_UNI & F_GOV \\
\hline \multirow[t]{2}{*}{ NEW_PDT } & 0.0189 & -0.0273 & 0.0089 & -0.0450 & 0.0001 & -0.0067 & 0.0510 & 0.0825 & 0.0887 & 0.0077 & 0.0742 & 0.0137 \\
\hline & 0.0401 & 0.0411 & 0.0365 & 0.0403 & 0305 & 0.0311 & $0.0262 *$ & $0.0307^{* * *}$ & $* 0.0311^{* * *}$ & * $\quad 0.0127$ & $0.0269 * * *$ & 0.0260 \\
\hline \multirow[t]{2}{*}{ IMP_PDT } & 0.0578 & -0.0965 & 1409 & & 0227 & & 0.1301 & & & & 0.0968 & 0.1015 \\
\hline & 0.0734 & 0.0724 & $0.0455^{* * *}$ & 0.0735 & 0.0631 & 0.0548 & $0.0762 *$ & 0.0638 & 0.0704 & 0.0418 & 0.0724 & 0.0727 \\
\hline \multirow[t]{2}{*}{ PDT_PRC } & 0.0421 & 0774 & 01646 & 0.1542 & 8624 & & 0.0908 & & & & 0.0887 & 0.1044 \\
\hline & 0.0491 & 0.0501 & $0.0470^{* * *}$ & $0.0483^{* * *}$ & 0.0364 * & & $0.0284^{* * *}$ & $0.0357 *$ & 0.0358 * & $0.0152^{* *}$ & $0.0294^{* * *}$ & $0.0303 * * *$ \\
\hline \multirow[t]{2}{*}{ INV_INT } & 0.0022 & -0.0078 & -0.0028 & 0.0004 & 0.0059 & 0.0066 & 0.0026 & 0.0 & 0.0012 & -0.0034 & 0.0028 & 0.0041 \\
\hline & 0.0020 & $0.0024^{* * *}$ & 0.0017 & 0.0 & $0.0014^{* * *}$ & $0.0016^{* * *}$ & 0.0011 ** & 0.0013 & & $0.0017^{* *}$ & $0.0010^{* * *}$ & 0.0011 \\
\hline \multirow[t]{2}{*}{ INV_MAC } & -0.0126 & 0.0038 & 0.0006 & -0.0049 & 0.0016 & -0.0078 & 0.0013 & -0.0077 & -0.0013 & -0.0035 & 0.0009 & 0.0020 \\
\hline & 0.0071 * & 0.0036 & 0.0038 & 0.0043 & 0.0027 & 0.0050 & 0.0022 & 0.0047 & 0.0027 & 0.0042 & 0.0023 & 0.0025 \\
\hline \multirow[t]{2}{*}{ INV_VAR } & -0.0100 & 0.0076 & 0.0368 & 0.0215 & 203 & & 0.0209 & 0.0489 & 0.0476 & 069 & 0.0307 & 0.0534 \\
\hline & 0.0113 & 0.0117 & $0.0107^{* * *}$ & $0.0113^{*}$ & $0.0083^{* *}$ & $0.0086^{* * *}$ & $0.0068^{* * *}$ & $0.0081^{* * *}$ & $* 0.0081^{* * *}$ & * $0.0037^{*}$ & $0.0069^{* * *}$ & $* 0.0072 *$ \\
\hline \multirow[t]{2}{*}{ SCIE } & 0.0806 & -0.0200 & 0.1462 & 0.0932 & -0.0585 & -0.0617 & -0.0537 & -0.0154 & -0.0305 & 0.0 & -0.0385 & -0.0194 \\
\hline & 0.0617 & 0.0606 & $0.0433^{* * *}$ & 0.0597 & $0.0350 *$ & 0.0372 * & $0.0262 * *$ & 0.0396 & & & 0.0292 & 0.0331 \\
\hline \multirow[t]{2}{*}{ COMPX } & -0.1771 & -0.0692 & 0.1175 & -0.0261 & -0.1345 & -0.1166 & -0.0912 & -0.1165 & -0.1073 & -0.0030 & -0.0482 & -0.1163 \\
\hline & $0.0883^{* *}$ & & 0.0772 & & $0.0347^{* * *}$ & $0.0538 * *$ & $0.0304^{* * *}$ & $0.0405^{* * *}$ & $* 0.0454^{* *}$ & 0.0330 & 0.0504 & 0.0240 * \\
\hline \multirow[t]{2}{*}{ PDT_ENG } & -0.0383 & -0.0273 & 0.1240 & 0.0258 & -0.0260 & -0.1047 & -0.0754 & -0.0243 & 0.0660 & -0.0008 & -0.0179 & 0.0150 \\
\hline & 0.0553 & 0.0582 & $0.0427^{* * *}$ & 0.0581 & 89 & $0.0330^{* * *}$ & $* 0.0238^{* * *}$ & 0.0380 & 0.0480 & 184 & 0.0330 & 0.0380 \\
\hline \multirow[t]{2}{*}{ FDT } & -0.0076 & -0.1491 & -0.0986 & -0.1943 & -0.0898 & -0.0347 & -0.0951 & -0.0333 & 0.1083 & -0.0110 & 0.0068 & -0.0044 \\
\hline & 0.0892 & $0.0902 *$ & & $0.0780 * *$ & 0.0501 * & & $0.0274^{* * *}$ & 0.0622 & & & 0.0626 & 0.0618 \\
\hline \multirow[t]{2}{*}{ SIZE } & 0.1262 & 0.0276 & 0.0116 & 0.0290 & 0.0446 & 0.0351 & 0.0502 & 0.0349 & 0.0336 & 0.0003 & 0.0351 & 0.0517 \\
\hline & $0.0165 *$ & $0.0165 *$ & 0.0147 & $0.0161 *$ & 0.0116 & 0.0122 & $* 0.0096 * * *$ & 0.0115 & 0.0115 * & 0.0051 & 0.0095 * & $0.0099 *$ \\
\hline \multirow[t]{2}{*}{ MKT } & 0.0329 & -0.0415 & 0.0721 & 0.0257 & 0.0798 & -0.0011 & 0.0249 & -0.0444 & -0.0271 & -0.0292 & 0.0747 & 0.0201 \\
\hline & 0.0397 & 0.0414 & $0.0380 *$ & 0.0408 & $0.0292 * * *$ & 0.0315 & 0.0246 & 0.0297 & 0.0298 & $0.0144^{* *}$ & $0.0240 * * *$ & 0.0251 \\
\hline
\end{tabular}

Obs: 766

Wald Chisq: $523.92^{* * *}$

Log Likelihood: -3741.53

Note: ${ }^{* *}$ significant at $1 \% ;{ }^{* *}$ significant at $5 \%,{ }^{*}$ significant at $10 \%$ 
Table 4: Multivariate Probit estimations (marginal effects) of reliance upon formal and informal external linkages. Results for The Netherlands.

\begin{tabular}{|c|c|c|c|c|c|c|c|c|c|c|c|c|}
\hline & INF_OT & INF_SUP & INF_CUST & INF_COMP & INF_UNI & INF_GOV & F_OT & F_SUP & F_CUST & F_COMP & F_UNI & F_GOV \\
\hline \multirow[t]{2}{*}{ NEW_PDT } & -0.010 & -0.036 & 0.124 & -0.029 & 0.033 & 0.014 & 0.035 & 0.039 & 0.031 & 0.001 & 0.005 & 0.018 \\
\hline & 0.027 & 0.028 & $0.028^{* * *}$ & 0.028 & $0.017^{*}$ & 0.019 & $0.014^{* *}$ & $0.015^{* * *}$ & $0.018 *$ & 0.010 & 0.007 & 0.011 \\
\hline \multirow[t]{2}{*}{ IMP_PDT } & 0.067 & -0.058 & 0.197 & 0.090 & 0.017 & 0.014 & 0.068 & 0.016 & 0.098 & -0.002 & 0.010 & 0.009 \\
\hline & 0.044 & 0.042 & $0.038^{* * *}$ & $0.044^{* *}$ & 0.032 & 0.033 & $0.034^{* *}$ & 0.031 & $0.040^{* *}$ & 0.018 & 0.019 & 0.022 \\
\hline \multirow[t]{2}{*}{ PDT_PRC } & 0.034 & -0.002 & 0.120 & 0.062 & 0.040 & 0.022 & 0.018 & 0.047 & 0.062 & 0.013 & 0.016 & 0.016 \\
\hline & 0.029 & 0.030 & $0.031^{* * *}$ & $0.030^{* *}$ & $0.018^{* *}$ & 0.021 & 0.015 & $0.016^{* * *}$ & $0.019^{* * *}$ & 0.011 & $0.008^{* *}$ & 0.012 \\
\hline \multirow[t]{2}{*}{ INV_INT } & 0.002 & -0.002 & 0.002 & 0.004 & 0.004 & 0.004 & 0.002 & 0.001 & 0.002 & 0.001 & 0.000 & 0.002 \\
\hline & 0.002 & 0.002 & 0.002 & $0.002 * *$ & $0.001^{* * *}$ & $0.001^{* * *}$ & $0.001^{* *}$ & 0.001 & 0.001 & $0.001 *$ & 0.000 & $0.001^{* * *}$ \\
\hline \multirow[t]{2}{*}{ INV_MAC } & 0.002 & 0.005 & 0.001 & 0.000 & -0.006 & -0.003 & -0.004 & -0.005 & -0.004 & -0.002 & -0.002 & -0.006 \\
\hline & 0.003 & 0.004 & 0.004 & 0.003 & $0.003 * *$ & 0.003 & 0.003 & $0.003 *$ & 0.003 & 0.002 & 0.001 & $0.002 * *$ \\
\hline \multirow[t]{2}{*}{ INV_VAR } & 0.013 & 0.018 & 0.023 & 0.028 & 0.016 & 0.020 & 0.012 & 0.018 & 0.017 & 0.007 & 0.005 & 0.012 \\
\hline & $0.006^{* *}$ & $0.006^{* * *}$ & $0.006^{* * *}$ & $0.006^{* * *}$ & $0.004^{* * *}$ & $0.004^{* * *}$ & $0.003^{* * *}$ & $0.003^{* * *}$ & $0.004^{* * *}$ & $0.002^{* * *}$ & $0.002^{* * *}$ & $0.002^{* * *}$ \\
\hline \multirow[t]{2}{*}{ SCIE } & 0.043 & -0.159 & 0.049 & 0.067 & 0.086 & -0.007 & -0.040 & -0.013 & 0.007 & -0.011 & 0.004 & 0.068 \\
\hline & 0.043 & $0.040^{* * *}$ & 0.044 & 0.045 & $0.034^{* *}$ & 0.029 & $0.013^{* * *}$ & 0.021 & 0.027 & 0.013 & 0.011 & $0.026^{* * *}$ \\
\hline \multirow[t]{2}{*}{ COMPX } & 0.013 & -0.015 & 0.133 & 0.010 & 0.060 & 0.014 & 0.031 & 0.024 & -0.014 & 0.049 & 0.003 & 0.046 \\
\hline & 0.056 & 0.058 & $0.055^{* *}$ & 0.058 & 0.043 & 0.042 & 0.031 & 0.034 & 0.032 & $0.029 *$ & 0.015 & 0.033 \\
\hline \multirow[t]{2}{*}{ PDT_ENG } & -0.066 & -0.076 & 0.104 & 0.053 & 0.022 & -0.021 & -0.027 & -0.001 & -0.027 & -0.022 & -0.003 & 0.010 \\
\hline & $0.034 *$ & $0.036^{* *}$ & $0.037^{* * *}$ & 0.038 & 0.025 & 0.024 & $0.014 *$ & 0.020 & 0.022 & $0.011^{* *}$ & 0.009 & 0.017 \\
\hline \multirow[t]{2}{*}{ FDT } & 0.132 & -0.059 & 0.028 & 0.001 & -0.007 & -0.020 & 0.001 & 0.022 & 0.046 & -0.013 & 0.006 & 0.033 \\
\hline & $0.037^{* * *}$ & $0.036 *$ & 0.037 & 0.036 & 0.022 & 0.023 & 0.017 & 0.021 & $0.026 *$ & 0.011 & 0.010 & $0.019 *$ \\
\hline \multirow[t]{2}{*}{ SIZE } & 0.076 & -0.011 & 0.017 & 0.038 & 0.026 & 0.037 & 0.021 & 0.024 & 0.025 & 0.012 & 0.010 & 0.024 \\
\hline & $0.010^{* * *}$ & 0.011 & 0.011 & $0.010^{* * *}$ & $0.006^{* * *}$ & $0.007^{* * *}$ & $0.005^{* * *}$ & $0.005^{* * *}$ & $0.006^{* * *}$ & $0.004^{* * *}$ & $0.002^{* * *}$ & $0.004^{* * *}$ \\
\hline \multirow[t]{2}{*}{ МКТ } & 0.101 & -0.006 & 0.062 & 0.015 & 0.032 & 0.012 & 0.005 & -0.018 & -0.023 & -0.017 & -0.007 & 0.018 \\
\hline & $0.026^{* * *}$ & 0.024 & $0.025^{* *}$ & 0.025 & 0.032 & 0.029 & 0.035 & 0.032 & 0.029 & 0.038 & 0.048 & 0.035 \\
\hline
\end{tabular}

Obs: 1633

Wald Chisq: $696.12^{* * *}$

Log Likelihood: -6981.42

Note: *** significant at $1 \%$; ** significant at $5 \%,{ }^{*}$ significant at $10 \%$ 
Table 5: Multivariate Probit estimations (marginal effects) of reliance upon formal and informal external linkages. Results for the UK.

\begin{tabular}{|c|c|c|c|c|c|c|c|c|c|c|c|c|}
\hline & INF_OT & INF_SUP & INF_CUST & INF_COMP & INF_UNI & INF_GOV & F_OT & F_SUP & F_CUST & F_COMP & F_UNI & F_GOV \\
\hline \multirow[t]{2}{*}{ NEW_PDT } & -0.006 & -0.130 & 0.126 & 0.000 & -0.001 & 0.001 & -0.014 & 0.023 & 0.067 & 0.018 & -0.009 & 0.030 \\
\hline & 0.038 & $0.037^{* * *}$ & $0.035^{* * *}$ & 0.036 & 0.026 & 0.016 & 0.013 & 0.023 & $0.026^{* * *}$ & 0.011 & 0.016 & $0.012 * *$ \\
\hline \multirow[t]{2}{*}{ IMP_PDT } & -0.062 & -0.182 & 0.059 & 0.131 & -0.019 & -0.024 & -0.038 & -0.035 & 0.062 & -0.002 & -0.014 & 0.026 \\
\hline & 0.046 & $0.047^{* * *}$ & 0.043 & $0.046^{* * *}$ & 0.031 & 0.016 & $0.014^{* * *}$ & 0.027 & $0.036 *$ & 0.015 & 0.019 & 0.020 \\
\hline \multirow[t]{2}{*}{ PDT_PRC } & 0.015 & 0.000 & -0.017 & 0.042 & -0.022 & -0.012 & 0.019 & 0.022 & 0.032 & 0.009 & -0.019 & 0.020 \\
\hline & 0.038 & 0.035 & 0.037 & 0.036 & 0.026 & 0.015 & 0.016 & 0.023 & 0.024 & 0.011 & 0.016 & $0.011 *$ \\
\hline \multirow[t]{2}{*}{ INV_INT } & 0.000 & -0.003 & -0.004 & 0.000 & 0.001 & 0.000 & 0.000 & -0.001 & -0.005 & 0.001 & 0.002 & 0.000 \\
\hline & 0.003 & 0.003 & 0.003 & 0.003 & 0.002 & 0.001 & 0.001 & 0.002 & $0.002 *$ & $0.001^{* *}$ & $0.001^{* *}$ & 0.001 \\
\hline \multirow[t]{2}{*}{ INV_MAC } & 0.007 & 0.013 & 0.003 & 0.003 & -0.001 & 0.001 & 0.000 & -0.002 & -0.003 & -0.001 & -0.002 & 0.000 \\
\hline & $0.003^{* * *}$ & $0.004^{* * *}$ & 0.003 & 0.003 & 0.002 & 0.001 & 0.001 & 0.002 & 0.002 & 0.001 & 0.002 & 0.001 \\
\hline \multirow[t]{2}{*}{ INV_VAR } & 0.028 & 0.015 & 0.039 & 0.026 & 0.035 & 0.012 & 0.014 & 0.039 & 0.035 & 0.007 & 0.028 & 0.007 \\
\hline & $0.011^{* *}$ & 0.010 & $0.011^{* * *}$ & $0.010 * *$ & $0.007^{* * *}$ & $0.004^{* * *}$ & $0.004^{* * *}$ & $0.006^{* * *}$ & $0.007^{* * *}$ & $0.003 * *$ & $0.005^{* * *}$ & $0.002 * * *$ \\
\hline \multirow[t]{2}{*}{ SCIE } & 0.051 & 0.033 & 0.106 & -0.041 & 0.013 & 0.020 & 0.014 & 0.035 & 0.041 & -0.024 & 0.020 & 0.021 \\
\hline & 0.045 & 0.038 & $0.040^{* * *}$ & 0.041 & 0.032 & 0.021 & 0.019 & 0.029 & 0.029 & $0.008^{* * *}$ & 0.021 & 0.014 \\
\hline \multirow[t]{2}{*}{ СОМРX } & 0.096 & 0.028 & 0.108 & 0.011 & 0.061 & 0.019 & -0.020 & 0.060 & -0.035 & -0.001 & 0.008 & 0.023 \\
\hline & $0.057^{*}$ & 0.049 & $0.050 * *$ & 0.053 & 0.046 & 0.027 & 0.018 & 0.041 & 0.030 & 0.013 & 0.027 & 0.019 \\
\hline \multirow[t]{2}{*}{ PDT_ENG } & -0.019 & 0.096 & 0.080 & 0.047 & 0.158 & 0.026 & -0.005 & 0.002 & 0.034 & -0.026 & 0.009 & 0.031 \\
\hline & 0.061 & $0.047^{* *}$ & 0.054 & 0.057 & $0.054^{* * *}$ & 0.031 & 0.022 & 0.035 & 0.039 & $0.006^{* * *}$ & 0.026 & 0.022 \\
\hline \multirow[t]{2}{*}{ FDT } & 0.122 & 0.035 & -0.035 & -0.090 & 0.043 & -0.001 & 0.010 & -0.008 & -0.002 & -0.011 & 0.075 & -0.004 \\
\hline & $0.057^{* *}$ & 0.048 & 0.054 & $0.049 *$ & 0.044 & 0.024 & 0.024 & 0.031 & 0.032 & 0.010 & $0.037^{* *}$ & 0.011 \\
\hline \multirow[t]{2}{*}{ SIZE } & 0.098 & 0.021 & 0.000 & 0.023 & 0.024 & 0.018 & 0.014 & 0.007 & 0.002 & 0.005 & 0.012 & 0.009 \\
\hline & $0.013^{* * *}$ & $0.011 *$ & 0.012 & $0.012 *$ & $0.009^{* * *}$ & $0.005^{* * *}$ & $0.005^{* * *}$ & 0.008 & 0.008 & $0.003 *$ & $0.005^{* *}$ & $0.003^{* * *}$ \\
\hline \multirow{2}{*}{ MKT } & 0.051 & -0.076 & 0.059 & 0.126 & 0.104 & 0.011 & 0.008 & 0.007 & -0.011 & 0.004 & 0.074 & 0.002 \\
\hline & 0.039 & $0.037 * *$ & 0.040 & $0.038^{* * *}$ & $0.044^{* *}$ & 0.058 & 0.059 & 0.047 & 0.046 & 0.069 & 0.048 & 0.062 \\
\hline
\end{tabular}

Obs: 1005

Wald Chisq: $547.34^{* * *}$

Log Likelihood: -4094.64

Note: ${ }^{* * *}$ significant at $1 \% ;{ }^{* *}$ significant at $5 \%,{ }^{*}$ significant at $10 \%$ 
Table 6: Cross country similarities and differences for the use of formal linkages

\begin{tabular}{|c|c|c|c|c|c|c|}
\hline & F_OT & F_SUP & F_CUST & F_COMP. & F_UNI. & F_GOV \\
\hline NEW_PDT & +++ & +++ & ++++ & + & +++ & +++ \\
\hline IMP_PDT & ++- & & ++ & & & \\
\hline PDT_PRC & + & +++ & +++ & + & +++ & ++ \\
\hline INV_INT & +++ & + & - & -++ & +++ & +++ \\
\hline INV_MAC & & - & & & & - \\
\hline INV_VAR & ++++ & ++++ & ++++ & +++ & ++++ & ++++ \\
\hline SCIE & -- & & & - & - & + \\
\hline COMPX & - & - & - & ++ & - & - \\
\hline PDT_ENG & -- & & & - & & \\
\hline FDT & - & & + & & + & + \\
\hline SIZE & ++++ & +++ & +++ & +++ & ++++ & ++++ \\
\hline МKT & & & & - & + & \\
\hline
\end{tabular}


Table 7: Cross country similarities and differences for the use of informal linkages

\begin{tabular}{|c|c|c|c|c|c|c|}
\hline & INF_OT & INF_SUP & INF_CUST & INF_COMP & INF_UNI & INF_GOV \\
\hline$\overline{N E W \_P D T}$ & & - & ++ & & + & \\
\hline IMP_PDT & + & - & +++ & ++ & - & \\
\hline PDT_PRC & & & ++ & ++ & ++ & \\
\hline INV_INT & & -- & + & + & +++ & ++ \\
\hline INV_MAC & -+ & + & & & - & \\
\hline INV_VAR & ++ & ++ & ++++ & ++++ & ++++ & ++++ \\
\hline SCIE & + & - & ++ & + & -+ & - \\
\hline COMPX & +-+ & & ++ & & - & - \\
\hline PDT_ENG & - & -+ & +++ & + & + & - \\
\hline FDT & ++ & -- & & -- & - & \\
\hline SIZE & ++++ & ++ & & ++++ & ++++ & ++++ \\
\hline $\mathrm{MKT}$ & + & -- & +++ & ++ & ++ & \\
\hline
\end{tabular}


LIST OF FIGURES

Figure 1: Distribution of linkages by innovation strategies

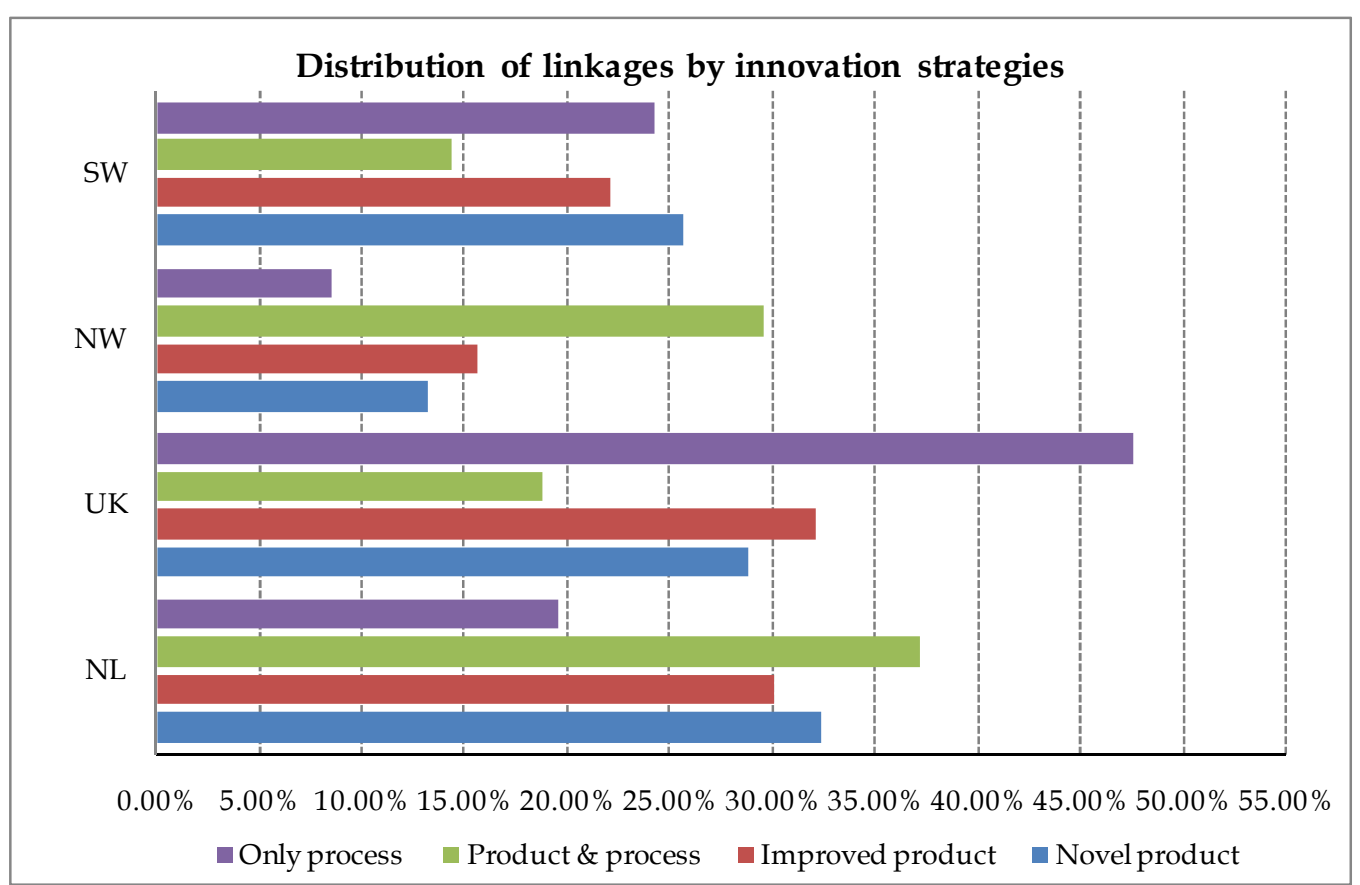

Each colour sums up to $100 \%$. 


\section{APPENDIX}

Table A1: Correlation matrix for the use of informal and formal linkages: Results for Sweden

\begin{tabular}{|c|c|c|c|c|c|c|c|c|c|c|c|c|}
\hline & Inf_ot & F_ot & Inf_sup & F_sup & Inf_cust & F_cust & Inf_comp & F_comp. & Inf_uni & F_uni. & Inf_gov & F_gov \\
\hline Inf_ot & 1 & 0.51 & 0.13 & 0.22 & . & 0.20 & . & . & . & . & . & . \\
\hline F_ot & & 1 & . & 0.55 & . & 0.51 & . & 0.37 & . & 0.37 & . & 0.30 \\
\hline Inf_sup & & & 1 & 0.20 & 0.28 & 0.16 & 0.23 & . & 0.20 & . & 0.25 & 0.17 \\
\hline F_sup & & & & 1 & . & 0.62 & . & 0.47 & . & 0.59 & . & 0.43 \\
\hline Inf_cust & & & & & 1 & 0.19 & 0.50 & . & 0.16 & . & 0.21 & . \\
\hline F_cust. & & & & & & 1 & . & 0.50 & 0.20 & 0.70 & . & 0.52 \\
\hline Inf_comp & & & & & & & 1 & 0.21 & 0.23 & . & 0.41 & . \\
\hline F_comp & & & & & & & & 1 & 0.24 & 0.52 & 0.22 & 0.46 \\
\hline Inf_uni & & & & & & & & & 1 & 0.43 & 0.66 & 0.33 \\
\hline F_uni. & & & & & & & & & & 1 & 0.33 & 0.65 \\
\hline Inf_gov & & & & & & & & & & & 1 & 0.55 \\
\hline F_gov & & & & & & & & & & & & 1 \\
\hline
\end{tabular}

Note: Only correlation coefficients significant at least at $5 \%$ are reported 
Table A2: Correlation matrix for the use of informal and formal linkages: Results for Norway

\begin{tabular}{|c|c|c|c|c|c|c|c|c|c|c|c|c|}
\hline & Inf_ot & F_ot & Inf_sup & F_sup & Inf_cust & F_cust & Inf_comp & F_comp. & Inf_uni & F_uni. & Inf_gov & F_gov \\
\hline Inf_ot & 1 & 0.46 & . & . & . & . & 0.14 & . & . & . & . & . \\
\hline F_ot & & 1 & . & 0.44 & . & 0.39 & . & 0.35 & . & 0.28 & 0.16 & 0.33 \\
\hline Inf_sup & & & 1 & 0.26 & . & . & 0.20 & . & . & . & . & . \\
\hline F_sup & & & & 1 & . & 0.60 & . & 0.53 & 0.24 & 0.48 & 0.17 & 0.48 \\
\hline Inf_cust & & & & & 1 & 0.34 & 0.44 & 0.28 & . & . & . & . \\
\hline F_cust. & & & & & & 1 & . & 0.66 & 0.31 & 0.55 & 0.16 & 0.51 \\
\hline Inf_comp & & & & & & & 1 & . & . & . & 0.14 & . \\
\hline F_comp & & & & & & & & 1 & 0.24 & 0.47 & 0.26 & 0.52 \\
\hline Inf_uni & & & & & & & & & 1 & 0.61 & 0.56 & 0.47 \\
\hline F_uni. & & & & & & & & & & 1 & 0.39 & 0.74 \\
\hline Inf_gov & & & & & & & & & & & 1 & 0.57 \\
\hline F_gov & & & & & & & & & & & & 1 \\
\hline
\end{tabular}

Note: Only correlation coefficients significant at least at $5 \%$ are reported 
Table A3: Correlation matrix for the use of informal and formal linkages: Results for the Netherlands

\begin{tabular}{|c|c|c|c|c|c|c|c|c|c|c|c|c|}
\hline & Inf_ot & F_ot & Inf_sup & F_sup & Inf_cust & F_cust & Inf_comp & F_comp. & Inf_uni & F_uni. & Inf_gov & F_gov \\
\hline Inf_ot & 1 & 0.28 & . & $\cdot$ & 0.08 & ${ }^{\circ}$ & 0.10 &. &. & 0.15 &. &. \\
\hline F_ot & & 1 & . & 0.50 & 0.11 & 0.57 & . & 0.54 & 0.25 & 0.41 & 0.21 & 0.55 \\
\hline Inf_sup & & & 1 & 0.32 & 0.18 & 0.15 & 0.15 & . & 0.17 & 0.17 & 0.15 & 0.16 \\
\hline F_sup & & & & 1 & 0.14 & 0.65 & . & 0.60 & 0.15 & 0.49 & 0.11 & 0.64 \\
\hline Inf_cust & & & & & 1 & 0.22 & 0.27 & 0.14 & 0.13 & 0.22 & 0.18 & 0.15 \\
\hline F_cust. & & & & & & 1 & . & 0.64 & . & 0.48 & . & 0.57 \\
\hline Inf_comp & & & & & & & 1 & 0.19 & 0.18 & 0.16 & 0.13 & . \\
\hline F_comp & & & & & & & & 1 & 0.17 & 0.47 & . & 0.56 \\
\hline Inf_uni & & & & & & & & & 1 & 0.21 & 0.66 & 0.49 \\
\hline F_uni. & & & & & & & & & & 1 & 0.28 & 0.51 \\
\hline Inf_gov & & & & & & & & & & & 1 & 0.33 \\
\hline F_gov & & & & & & & & & & & & 1 \\
\hline
\end{tabular}

Note: Only correlation coefficients significant at least at $5 \%$ are reported 
Table A4: Correlation matrix for the use of informal and formal linkages: Results for the UK

\begin{tabular}{|c|c|c|c|c|c|c|c|c|c|c|c|c|}
\hline & Inf_ot & F_ot & Inf_sup & F_sup & Inf_cust & F_cust & Inf_comp & F_comp. & Inf_uni & F_uni. & Inf_gov & F_gov \\
\hline Inf_ot & 1 & 0.27 & . & . & 0.20 & 0.21 & 0.24 & 0.22 & 0.17 & & 0.32 & . \\
\hline F_ot & & 1 & . & 0.48 & . & 0.49 & . & 0.45 & 0.18 & 0.40 & . & 0.36 \\
\hline Inf_sup & & & 1 & 0.22 & 0.21 & . & 0.14 & . & 0.18 & . & 0.16 & 0.18 \\
\hline F_sup & & & & 1 & 0.13 & 0.70 & . & 0.66 & . & 0.56 & . & 0.58 \\
\hline Inf_cust & & & & & 1 & 0.32 & 0.47 & 0.22 & 0.21 & 0.21 & 0.32 & 0.35 \\
\hline F_cust. & & & & & & 1 & . & 0.74 & 0.16 & 0.60 & 0.19 & 0.61 \\
\hline Inf_comp & & & & & & & 1 & 0.25 & 0.16 & . & 0.31 & . \\
\hline F_comp & & & & & & & & 1 & . & 0.44 & 0.23 & 0.54 \\
\hline Inf_uni & & & & & & & & & 1 & 0.57 & 0.38 & 0.31 \\
\hline F_uni. & & & & & & & & & & 1 & 0.29 & 0.58 \\
\hline Inf_gov & & & & & & & & & & & 1 & 0.68 \\
\hline F_gov & & & & & & & & & & & & 1 \\
\hline
\end{tabular}

Note: Only correlation coefficients significant at least at 5\% are reported 